\title{
A Comparative Study on Chemical Composition, Antileishmanial and Cytotoxic Activities of the Essential Oils from Leaves of Guarea macrophylla (Meliaceae) from Two Different Regions of São Paulo State, Brazil, Using Multivariate Statistical Analysis
}

\author{
Emerson A. Oliveira, ${ }^{a}$ Euder G. A. Martins, ${ }^{b}$ Marisi G. Soares, ${ }^{c}$ Daniela A. Chagas-Paula, ${ }^{c}$ \\ Luiz F. D. Passero, ${ }^{d}$ Patricia Sartorelli, ${ }^{a}$ João L. Baldim ${ }^{*, e}$ and João Henrique G. Lago ${ }^{\circledR *, e}$ \\ anstituto de Ciências Ambientais, Químicas e Farmacêuticas, Universidade Federal de São Paulo, \\ 09972-270 Diadema-SP, Brazil \\ ${ }^{b}$ Instituto de Biociências, Universidade de São Paulo, 05508-090 São Paulo-SP, Brazil \\ 'Instituto de Química, Universidade Federal de Alfenas, 37130-001 Alfenas-MG, Brazil \\ ${ }^{d}$ Instituto de Biociências e Instituto de Estudos Avançados do Mar, Universidade Estadual Paulista, \\ 11330-900 São Vicente-SP, Brazil \\ ${ }^{e}$ Centro de Ciências Naturais e Humanas, Universidade Federal do ABC, \\ 09210-580 Santo André-SP, Brazil
}

\begin{abstract}
Meliaceae representatives are economically important in several aspects including the production of highly prized woods (mahogany, cedar, etc.), constituents for cosmetics, and insecticides. The present study aimed to verify the chemical composition as well as leishmanicidal and cytotoxic potential of essential oils from leaves of two different populations of Guarea macrophylla collected at cities of São Paulo (population I) and Cubatão (population II), São Paulo State, Brazil. Chemically, the oils showed the predominance of sesquiterpenes: cis- $\beta$-guaiene, bicyclogermacrene, viridiflorol, and isolongifolan- $7 \alpha$-ol from population I and $\alpha$-copaene, $E$-caryophyllene, cis- $\beta$-guaiene, and $\gamma$-amorphene from population II. In vitro antileishmanial activity against promastigote forms of Leishmania (L.) amazonensis of essential oils was evaluated and displayed $50 \%$ effective concentration $\left(\mathrm{EC}_{50}\right)$ values ranging from 11.8 to $20.5 \mu \mathrm{g} \mathrm{mL} \mathrm{m}^{-1}$. Furthermore, toxicity against peritoneal macrophages of BALB/c mice was observed, with $50 \%$ cytotoxic concentration $\left(\mathrm{CC}_{50}\right)$ ranging from 17.7 to $>100 \mu \mathrm{g} \mathrm{mL} \mathrm{m}^{-1}$. Multivariate statistical analysis revealed the influence of each constituent of the oils against $L$. amazonensis being 1,10-di-epi-cubenol, $\alpha$-amorphene, $E$-caryophyllene, isopimara-7,15-diene, and $\beta$-elemene associated with the antileishmanial potential.
\end{abstract}

Keywords: Guarea macrophylla, 1,10-di-epi-cubenol, multivariate statistical analysis, antileishmanial activity

\section{Introduction}

Species of Meliaceae are largely used for the production of bio-oils, cosmetic products (andiroba), insecticides (neem) and highly prized wood (mahogany, cedar, etc). ${ }^{1-4}$ Chemically, Meliaceae species produce different classes of secondary metabolites, including terpenoids, lactones, steroids, limonoids, etc., which display several biological activities. ${ }^{2,4}$ Belonging to Meliaceae, Guarea macrophylla is composed of triterpenes, ${ }^{5}$ diterpenes, ${ }^{6,7}$ sesquiterpenes, ${ }^{6}$

*e-mail: jotaelebaldim@gmail.com; joao.lago@ufabc.edu.br flavonoids, and lignoids. ${ }^{8}$ The essential oils from fruits, ${ }^{9}$ stem barks, ${ }^{10}$ and leaves ${ }^{11}$ were chemically analyzed and a predominance of sesquiterpenes and diterpenes was observed. However, no information concerning the biological aspects of these oils was previously reported in the literature, except the effects of leaves oil on the mahogany shoot borer, Hypsipyla grandella. ${ }^{12}$

Leishmaniasis is an infectious disease with high morbidity and mortality, affecting millions of people worldwide, mostly in Latin American countries. ${ }^{13,14}$ The clinical treatment includes pentavalent antimonials, amphotericin B, paromomycin, miltefosine, and 
pentamidine, with several side effects. ${ }^{15}$ Based on this aspect, the discovery of new bioactive compounds for the treatment of leishmaniasis is crucial and could be performed using natural products. ${ }^{16,17}$ At this point, essential oils could be considered as an important source of bioactive compounds due to the antimicrobial, antioxidant, antiviral, and antiparasitic effects. ${ }^{18}$ As part of our continuous study to the discovery of antiparasitic natural products, ${ }^{19}$ the essential oils from leaves of G. macrophylla from two different populations (São Paulo (SP) and Cubatão (CB) cities) were chemically analyzed and tested in vitro against promastigote forms of L. amazonensis. In order to measure the importance of the identified constituents of essential oils to the antileishmanial activity, a multivariate statistical analysis (MSA) and machine learning approaches were performed. The validation and interpretation of the results led to the selection of main attributes for an effective antileishmanial property of essential oils from leaves of G. macrophylla.

\section{Results and Discussion}

The essential oils from leaves of G. macrophylla, collected quarterly during one year from two different regions (SP, population I, and CB, population II) were individually obtained by hydrodistillation using a Clevenger apparatus. Their respective yields, calculated based on the fresh weight of the leaves, are indicated in Table 1.

The identification of the individual compounds of each oil (Table 2) was achieved by interpretation of mass spectra and also by calculation of their respective Kovats indices, determined relative to the retention times of a series of $n$-alkanes. ${ }^{20}$

Chemically, the essential oils from leaves of G. macrophylla showed, as the major constituent in all studied samples, the sesquiterpene cis- $\beta$-guaiene (ranging from $6.61 \pm 0.04$ to $18.17 \pm 0.02 \%$ ). Besides, the oils from leaves of population I (SP) were composed of high concentrations of bicyclogermacrene $(7.07 \pm 0.01-12.78 \pm 0.04 \%)$, isolongifolan- $7 \alpha$-ol $(6.63 \pm 0.02-10.85 \pm 0.05 \%)$, viridiflorol $(6.34 \pm 0.02-8.49 \pm 0.03 \%)$, and manoyl oxide $(3.49 \pm 0.01-7.61 \pm 0.02 \%)$, a different profile of that previously investigated, ${ }^{11}$ in which guai-6-en-10ß-ol (17.3\%) and ledol (13.9\%) were identified as main compounds. The oils from leaves from population II (CB) were composed mostly of $E$-caryophyllene $(9.61 \pm 0.02-18.84 \pm 0.04 \%)$, $\alpha$-copaene $(4.63 \pm 0.03-14.06 \pm 0.03 \%)$, $\delta$-amorphene $(3.93 \pm 0.01-7.55 \pm 0.02 \%)$, palustrol (3.75 $\pm 0.01-4.74 \pm 0.01 \%)$, isopimara-7,15-dien-3 $\beta$-ol $(2.22 \pm 0.01-7.57 \pm 0.02 \%)$, and 1,10-di-epi-cubenol $(1.70 \pm 0.02-5.17 \pm 0.03 \%)$, as indicated in Table 2. The predominance of sesquiterpenoids associated with the absence of monoterpenes is in accordance with previous studies of chemical composition of essential oils from leaves, stem barks and fruits of G. macrophylla. ${ }^{9-11}$ However, despite a previous study indicating a quantitative chemical variation of the volatile constituents from leaves of G. macrophylla, ${ }^{21}$ this is the first analysis of two different populations which showed a qualitative variation. As shown in Table 2, the oils from population I (SP) exhibited higher complexity in comparison with the oils obtained from population II (CB), including some exclusive sesquiterpenes, such as 1-epi-cubenol $(1.65 \pm 0.01-2.64 \pm 0.00 \%)$, $\delta$-cadinene $(0.93 \pm 0.02-2.30 \pm 0.01 \%)$, $\alpha$-ylangene $(0.92 \pm 0.00-1.83 \pm 0.01 \%)$, $\alpha$-cadinene $(0.53 \pm 0.00-1.29 \pm 0.01 \%)$, hinesol $(0.30 \pm 0.01-1.08 \pm 0.00 \%), \alpha$-acorenol $(0.47 \pm 0.01-0.60 \pm 0.00 \%)$, and valerianol $(0.29 \pm 0.00-0.52 \pm 0.00 \%)$. Therefore, our results indicated an expressive variation on the chemical composition of the essential oils from leaves of two different populations of G. macrophylla, which could directly affect the biological potential of these oils.

Based on evidence that essential oils showed in vitro anti-leishmanial effects, ${ }^{22,23}$ the obtained crude oils from leaves of G. macrophylla from populations I (SP-1 to SP-5) and II (CB-1 to CB-5) were evaluated against promastigote forms of L. amazonensis (Table 3).

Table 1. Collection dates and yields of essential oils from leaves of G. macrophylla collected in São Paulo (population I) and Cubatão (population II)

\begin{tabular}{|c|c|c|c|c|c|}
\hline \multicolumn{3}{|c|}{ Population I (SP) } & \multicolumn{3}{|c|}{ Population II (CB) } \\
\hline Date of collection & Sample & Yield / \% & Date of collection & Sample & Yield / \% \\
\hline $02 / 15 / 2013$ & SP-1 & 0.40 & $02 / 16 / 2013$ & CB-1 & 0.31 \\
\hline $05 / 13 / 2013$ & SP-2 & 0.29 & $05 / 12 / 2013$ & CB-2 & 0.25 \\
\hline $08 / 18 / 2013$ & SP-3 & 0.21 & $08 / 17 / 2013$ & CB-3 & 0.17 \\
\hline $11 / 02 / 2013$ & SP-4 & 0.19 & $11 / 03 / 2013$ & CB-4 & 0.13 \\
\hline $02 / 15 / 2014$ & SP-5 & 0.40 & $02 / 16 / 2014$ & CB-5 & 0.33 \\
\hline
\end{tabular}

SP: São Paulo; CB: Cubatão. 
Table 2. Chemical composition of essential oils from leaves of G. macrophylla collected in São Paulo (population I) and Cubatão (population II)

\begin{tabular}{|c|c|c|c|c|c|c|c|c|c|c|c|}
\hline \multirow{3}{*}{ KI } & \multirow{3}{*}{ Compound } & \multicolumn{10}{|c|}{ Relative amount \pm SD / \% } \\
\hline & & \multicolumn{5}{|c|}{ Population $\mathrm{I}^{\mathrm{a}}$} & \multicolumn{5}{|c|}{ Population $\mathrm{II}^{\mathrm{a}}$} \\
\hline & & SP-1 & SP-2 & SP-3 & SP-4 & SP-5 & CB-1 & $\mathrm{CB}-2$ & CB-3 & $\mathrm{CB}-4$ & CB-5 \\
\hline 1351 & $\alpha$-cubebene & $0.46 \pm 0.01$ & $0.43 \pm 0.00$ & $0.26 \pm 0.01$ & $1.12 \pm 0.02$ & $0.66 \pm 0.00$ & $2.44 \pm 0.01$ & $2.93 \pm 0.03$ & $1.10 \pm 0.01$ & $2.47 \pm 0.01$ & - \\
\hline 1371 & cyclosativene & $0.40 \pm 0.00$ & $0.36 \pm 0.00$ & $0.30 \pm 0.00$ & $0.22 \pm 0.00$ & - & - & - & - & - & - \\
\hline 1375 & $\alpha$-ylangene & $1.83 \pm 0.01$ & $1.75 \pm 0.01$ & $1.28 \pm 0.01$ & $0.92 \pm 0.00$ & $1.80 \pm 0.02$ & - & - & - & - & - \\
\hline 1376 & $\alpha$-copaene & $0.83 \pm 0.00$ & $0.97 \pm 0.01$ & $0.52 \pm 0.00$ & $1.92 \pm 0.02$ & $1.08 \pm 0.01$ & $12.35 \pm 0.02$ & $14.06 \pm 0.03$ & $4.63 \pm 0.03$ & $10.82 \pm 0.04$ & $13.75 \pm 0.04$ \\
\hline 1390 & $\beta$-elemene & $1.23 \pm 0.01$ & $1.67 \pm 0.02$ & $1.73 \pm 0.01$ & $1.47 \pm 0.01$ & $1.31 \pm 0.01$ & - & $0.81 \pm 0.00$ & $1.10 \pm 0.01$ & $1.04 \pm 0.01$ & - \\
\hline 1409 & $\alpha$-gurjunene & $0.54 \pm 0.00$ & $0.64 \pm 0.00$ & $0.46 \pm 0.01$ & $0.65 \pm 0.01$ & $0.58 \pm 0.00$ & - & $0.69 \pm 0.01$ & - & - & $5.70 \pm 0.01$ \\
\hline 1419 & $E$-caryophyllene & $1.59 \pm 0.01$ & $1.71 \pm 0.02$ & $1.31 \pm 0.01$ & $2.56 \pm 0.01$ & $3.15 \pm 0.02$ & $9.61 \pm 0.02$ & $10.65 \pm 0.04$ & $12.14 \pm 0.05$ & $18.84 \pm 0.04$ & $13.22 \pm 0.05$ \\
\hline 1441 & aromadendrene & - & $0.13 \pm 0.00$ & - & - & - & - & - & - & - & - \\
\hline 1444 & 6,9 -guaiadiene & - & $0.20 \pm 0.00$ & - & $0.47 \pm 0.00$ & - & - & - & - & - & - \\
\hline 1454 & $\alpha$-humulene & $0.45 \pm 0.00$ & $0.52 \pm 0.01$ & $0.41 \pm 0.01$ & - & $0.49 \pm 0.00$ & - & - & - & - & - \\
\hline 1460 & allo-aromadendrene & $1.71 \pm 0.00$ & $1.80 \pm 0.02$ & $1.49 \pm 0.01$ & $1.83 \pm 0.01$ & $1.93 \pm 0.02$ & - & - & $0.74 \pm 0.02$ & - & - \\
\hline 1479 & $\gamma$-muurolene & $3.28 \pm 0.02$ & $3.40 \pm 0.03$ & $2.96 \pm 0.03$ & $2.23 \pm 0.01$ & $2.65 \pm 0.02$ & $1.42 \pm 0.01$ & $1.21 \pm 0.01$ & $1.57 \pm 0.02$ & $1.08 \pm 0.02$ & $1.40 \pm 0.01$ \\
\hline 1481 & germacrene D & $0.26 \pm 0.00$ & - & - & $0.38 \pm 0.02$ & $0.29 \pm 0.02$ & - & - & $0.57 \pm 0.01$ & - & $0.88 \pm 0.00$ \\
\hline 1482 & $\gamma$-himachalene & $0.41 \pm 0.00$ & $0.70 \pm 0.00$ & $0.58 \pm 0.01$ & $0.36 \pm 0.01$ & $0.37 \pm 0.01$ & $1.45 \pm 0.01$ & $2.69 \pm 0.01$ & $0.88 \pm 0.00$ & $1.34 \pm 0.01$ & $2.30 \pm 0.02$ \\
\hline 1484 & $\alpha$-amorphene & $1.74 \pm 0.02$ & $2.46 \pm 0.01$ & $2.06 \pm 0.00$ & $1.72 \pm 0.01$ & $2.12 \pm 0.02$ & $1.42 \pm 0.01$ & $1.63 \pm 0.01$ & $1.78 \pm 0.01$ & $3.43 \pm 0.01$ & - \\
\hline 1493 & $\begin{array}{l}\text { trans-muurola- } \\
\text { 4(14),5-diene }\end{array}$ & - & $0.15 \pm 0.00$ & - & - & - & - & - & - & - & - \\
\hline 1493 & $c i s-\beta$-guaiene & $6.71 \pm 0.03$ & $7.59 \pm 0.02$ & $6.61 \pm 0.04$ & $17.59 \pm 0.07$ & $10.19 \pm 0.07$ & $15.02 \pm 0.03$ & $18.15 \pm 0.04$ & $13.09 \pm 0.04$ & $18.17 \pm 0.02$ & $7.51 \pm 0.02$ \\
\hline 1500 & bicyclogermacrene & $7.20 \pm 0.04$ & $12.76 \pm 0.04$ & $11.86 \pm 0.07$ & $7.07 \pm 0.01$ & $12.78 \pm 0.04$ & - & - & $4.98 \pm 0.02$ & - & - \\
\hline 1502 & trans- $\beta$-guaiene & $1.87 \pm 0.01$ & $1.56 \pm 0.01$ & $1.44 \pm 0.01$ & $1.51 \pm 0.01$ & $1.91 \pm 0.01$ & $2.52 \pm 0.01$ & $1.82 \pm 0.01$ & $1.83 \pm 0.01$ & $1.62 \pm 0.01$ & $1.24 \pm 0.01$ \\
\hline 1512 & $\delta$-amorphene & $2.72 \pm 0.01$ & $2.84 \pm 0.01$ & $2.31 \pm 0.01$ & $3.18 \pm 0.01$ & $2.79 \pm 0.01$ & $5.83 \pm 0.02$ & $6.61 \pm 0.01$ & $3.93 \pm 0.01$ & $5.40 \pm 0.02$ & $7.55 \pm 0.02$ \\
\hline 1513 & $\begin{array}{l}\text { trans-cyclosolongin- } \\
5 \text {-ol }\end{array}$ & - & $1.69 \pm 0.00$ & $1.06 \pm 0.01$ & $3.59 \pm 0.01$ & $2.31 \pm 0.01$ & - & $1.04 \pm 0.01$ & $1.03 \pm 0.01$ & $1.03 \pm 0.01$ & $2.90 \pm 0.01$ \\
\hline 1513 & $\gamma$-cadinene & - & - & - & - & $0.30 \pm 0.00$ & - & - & - & - & - \\
\hline 1523 & $\delta$-cadinene & $2.30 \pm 0.01$ & $1.23 \pm 0.00$ & $1.42 \pm 0.02$ & $0.93 \pm 0.02$ & $0.96 \pm 0.00$ & - & - & - & - & - \\
\hline 1534 & $\begin{array}{l}\text { trans-cadina- } \\
\text { 1,4-diene }\end{array}$ & $0.53 \pm 0.00$ & - & - & $0.35 \pm 0.01$ & - & - & - & - & - & - \\
\hline 1538 & $\alpha$-cadinene & $1.29 \pm 0.01$ & $0.79 \pm 0.00$ & $0.87 \pm 0.02$ & $0.53 \pm 0.00$ & $0.94 \pm 0.00$ & - & - & - & - & - \\
\hline 1545 & $\alpha$-calacorene & $1.63 \pm 0.00$ & $1.89 \pm 0.01$ & $1.42 \pm 0.01$ & $2.55 \pm 0.00$ & $2.65 \pm 0.01$ & - & $1.07 \pm 0.01$ & $1.13 \pm 0.01$ & $1.00 \pm 0.00$ & $0.55 \pm 0.00$ \\
\hline 1546 & selina-3,7(11)-diene & $0.28 \pm 0.00$ & - & - & - & - & - & - & - & - & - \\
\hline 1548 & hedycarvol & $1.46 \pm 0.01$ & $1.64 \pm 0.01$ & $1.56 \pm 0.00$ & $1.22 \pm 0.01$ & $1.43 \pm 0.01$ & - & $0.65 \pm 0.01$ & $0.88 \pm 0.01$ & - & $1.04 \pm 0.01$ \\
\hline 1549 & elemol & $0.63 \pm 0.00$ & - & $0.22 \pm 0.00$ & - & - & - & - & - & - & - \\
\hline 1561 & germacrene B & $1.33 \pm 0.00$ & $0.50 \pm 0.00$ & $0.63 \pm 0.00$ & $0.96 \pm 0.01$ & $0.55 \pm 0.00$ & $1.90 \pm 0.01$ & $0.92 \pm 0.00$ & $0.66 \pm 0.01$ & - & $0.72 \pm 0.00$ \\
\hline 1565 & $\beta$-calacorene & - & $0.69 \pm 0.00$ & - & - & - & - & - & - & - & - \\
\hline 1568 & palustrol & $1.37 \pm 0.01$ & $1.13 \pm 0.01$ & $1.37 \pm 0.01$ & $2.07 \pm 0.01$ & $1.81 \pm 0.00$ & $3.75 \pm 0.01$ & $4.74 \pm 0.01$ & $4.70 \pm 0.02$ & $3.96 \pm 0.02$ & $4.26 \pm 0.02$ \\
\hline 1578 & spathulenol & $0.95 \pm 0.00$ & $0.67 \pm 0.00$ & $0.92 \pm 0.01$ & $1.30 \pm 0.01$ & $1.21 \pm 0.00$ & $1.75 \pm 0.01$ & $2.16 \pm 0.01$ & $1.76 \pm 0.01$ & $1.46 \pm 0.01$ & $1.76 \pm 0.00$ \\
\hline 1592 & viridiflorol & $7.21 \pm 0.04$ & $8.37 \pm 0.02$ & $8.49 \pm 0.03$ & $6.34 \pm 0.02$ & $7.46 \pm 0.02$ & $2.15 \pm 0.00$ & $1.33 \pm 0.02$ & $4.07 \pm 0.01$ & $1.46 \pm 0.01$ & $2.15 \pm 0.01$ \\
\hline 1600 & guaiol & $3.16 \pm 0.02$ & $3.38 \pm 0.01$ & $3.45 \pm 0.01$ & $2.47 \pm 0.01$ & $3.26 \pm 0.00$ & - & - & - & - & - \\
\hline 1602 & ledol & $0.89 \pm 0.00$ & $0.40 \pm 0.00$ & - & - & - & $0.92 \pm 0.01$ & $0.90 \pm 0.02$ & - & $0.64 \pm 0.01$ & $0.82 \pm 0.00$ \\
\hline 1619 & 1,10-di-epi-cubenol & - & $3.85 \pm 0.01$ & - & - & - & $2.42 \pm 0.01$ & $2.32 \pm 0.01$ & $5.17 \pm 0.03$ & $1.70 \pm 0.02$ & $2.33 \pm 0.01$ \\
\hline 1619 & isolongifolan-7- $\alpha$-ol & $8.86 \pm 0.03$ & $6.63 \pm 0.02$ & $10.85 \pm 0.05$ & $8.58 \pm 0.02$ & $10.71 \pm 0.02$ & - & - & $1.35 \pm 0.01$ & - & - \\
\hline 1628 & 1-epi-cubenol & $1.86 \pm 0.00$ & $2.01 \pm 0.01$ & $2.03 \pm 0.02$ & $1.65 \pm 0.01$ & $2.64 \pm 0.00$ & - & - & - & - & - \\
\hline 1631 & erenoligenol & $1.63 \pm 0.01$ & $1.79 \pm 0.01$ & $1.78 \pm 0.01$ & $1.73 \pm 0.01$ & $2.01 \pm 0.01$ & $2.03 \pm 0.01$ & $3.18 \pm 0.02$ & $2.15 \pm 0.01$ & $1.68 \pm 0.01$ & $2.65 \pm 0.01$ \\
\hline 1633 & $\alpha$-acorenol & $0.53 \pm 0.00$ & $0.56 \pm 0.00$ & $0.47 \pm 0.01$ & $0.48 \pm 0.00$ & $0.60 \pm 0.00$ & - & - & - & - & - \\
\hline 1636 & cis-cadin-4-en-7-ol & $2.18 \pm 0.00$ & $1.87 \pm 0.02$ & $2.06 \pm 0.01$ & $1.77 \pm 0.00$ & $2.15 \pm 0.01$ & $1.26 \pm 0.01$ & $1.19 \pm 0.01$ & $1.85 \pm 0.02$ & $1.02 \pm 0.01$ & $0.90 \pm 0.00$ \\
\hline
\end{tabular}


Table 2. Chemical composition of essential oils from leaves of G. macrophylla collected in São Paulo (population I) and Cubatão (population II) (cont.)

\begin{tabular}{|c|c|c|c|c|c|c|c|c|c|c|c|}
\hline \multirow{3}{*}{ KI } & \multirow{3}{*}{ Compound } & \multicolumn{10}{|c|}{ Relative amount $\pm \mathrm{SD} / \%$} \\
\hline & & \multicolumn{5}{|c|}{ Population I ${ }^{\mathrm{a}}$} & \multicolumn{5}{|c|}{ Population II ${ }^{\mathrm{a}}$} \\
\hline & & SP-1 & SP-2 & SP-3 & SP-4 & SP-5 & CB-1 & $\mathrm{CB}-2$ & CB-3 & CB-4 & CB-5 \\
\hline 1641 & hinesol & $1.08 \pm 0.00$ & $0.32 \pm 0.00$ & $0.30 \pm 0.01$ & $0.30 \pm 0.00$ & $0.37 \pm 0.00$ & - & - & - & - & - \\
\hline 1646 & cubenol & - & $0.10 \pm 0.00$ & - & - & - & - & - & - & - & - \\
\hline 1651 & cedr- $8(15)$-en- $9 \alpha$-ol & - & $0.11 \pm 0.00$ & - & - & - & - & - & - & - & - \\
\hline 1653 & $\alpha$-eudesmol & - & $0.10 \pm 0.00$ & - & - & - & - & - & - & - & - \\
\hline 1658 & valerianol & $0.52 \pm 0.00$ & $0.37 \pm 0.01$ & $0.40 \pm 0.01$ & $0.29 \pm 0.00$ & $0.42 \pm 0.00$ & - & - & - & - & - \\
\hline 1663 & 7-epi- $\alpha$-eudesmol & $0.33 \pm 0.00$ & - & - & - & - & - & - & - & - & - \\
\hline 1949 & $\begin{array}{l}\text { isopimara- } \\
7,15 \text {-diene }\end{array}$ & $0.66 \pm 0.00$ & $0.51 \pm 0.00$ & $0.60 \pm 0.01$ & $0.48 \pm 0.00$ & - & $1.25 \pm 0.01$ & $0.93 \pm 0.01$ & $1.03 \pm 0.01$ & $1.58 \pm 0.02$ & $0.54 \pm 0.00$ \\
\hline 1987 & manoyl oxide & $7.61 \pm 0.02$ & $5.45 \pm 0.02$ & $6.80 \pm 0.02$ & $5.36 \pm 0.01$ & $3.49 \pm 0.01$ & - & - & $2.92 \pm 0.01$ & - & - \\
\hline 2000 & 13-epi-dolabradiene & $0.29 \pm 0.00$ & $0.24 \pm 0.00$ & $0.23 \pm 0.00$ & - & - & - & - & - & - & - \\
\hline 2017 & phyllocladene & - & - & $0.27 \pm 0.00$ & - & - & - & - & - & - & - \\
\hline 2161 & 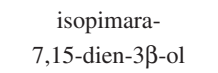 & $1.24 \pm 0.00$ & $0.84 \pm 0.00$ & $0.94 \pm 0.01$ & $0.81 \pm 0.00$ & $0.76 \pm 0.00$ & $7.57 \pm 0.02$ & $2.72 \pm 0.01$ & $4.77 \pm 0.02$ & $3.26 \pm 0.02$ & $2.22 \pm 0.01$ \\
\hline 2184 & sandaracopimarinal & - & $0.29 \pm 0.00$ & $0.38 \pm 0.00$ & $0.54 \pm 0.00$ & $0.41 \pm 0.00$ & - & $0.72 \pm 0.01$ & - & $0.76 \pm 0.00$ & $0.71 \pm 0.00$ \\
\hline 2279 & $\begin{array}{c}\text { isopimara- } \\
\text { 7,15-dien-3-one }\end{array}$ & $5.29 \pm 0.01$ & $2.89 \pm 0.02$ & $4.08 \pm 0.02$ & $2.97 \pm 0.03$ & $2.49 \pm 0.03$ & $1.65 \pm 0.01$ & $0.42 \pm 0.01$ & $2.07 \pm 0.02$ & - & $0.57 \pm 0.00$ \\
\hline 2284 & $\begin{array}{c}\text { isopimara- } \\
7,15 \text {-dien- } 2 \alpha \text {-ol }\end{array}$ & $2.20 \pm 0.01$ & $1.26 \pm 0.01$ & $1.74 \pm 0.00$ & $1.24 \pm 0.01$ & $1.14 \pm 0.00$ & - & - & $0.75 \pm 0.00$ & - & - \\
\hline 2412 & $\begin{array}{c}\text { labda-8,13E-dien- } \\
15 \text {-ol }\end{array}$ & $0.71 \pm 0.00$ & $0.41 \pm 0.00$ & $0.73 \pm 0.00$ & $0.48 \pm 0.00$ & - & - & - & - & - & - \\
\hline & Total identified & $91.28 \pm 0.05$ & $93.62 \pm 0.04$ & $90.66 \pm 0.05$ & $94.19 \pm 0.07$ & $94.16 \pm 0.07$ & $78.72 \pm 0.03$ & $85.57 \pm 0.04$ & $84.62 \pm 0.05$ & $83.78 \pm 0.04$ & $77.67 \pm 0.05$ \\
\hline
\end{tabular}

KI: experimental Kovats index; SD: standard deviation; SP: São Paulo; CB: Cubatão; -: not detected. The identified constituents are listed in order of their KI values. ${ }^{\text {a Collections }}$ from 1 to 5 from population I (São Paulo) and II (Cubatão).

Table 3. Antileishmanial activity, cytotoxicity and selectivity indices (SI) of the essential oils from different collections of leaves of G. macrophylla

\begin{tabular}{lccc}
\hline Collection & $\mathrm{EC}_{50}{ }^{\mathrm{a}} /\left(\mu \mathrm{g} \mathrm{mL}^{-1}\right)$ & $\mathrm{CC}_{50}{ }^{\mathrm{b}} /\left(\mu \mathrm{g} \mathrm{mL}^{-1}\right)$ & $\mathrm{SI}$ \\
\hline SP-1 & $16.5 \pm 2.7$ & $87.0 \pm 1.8$ & 5.3 \\
$\mathrm{SP}-2$ & $11.8 \pm 5.2$ & $75.6 \pm 6.1$ & 6.4 \\
SP-3 & $16.5 \pm 2.0$ & $78.5 \pm 9.4$ & 4.8 \\
SP-4 & $16.4 \pm 2.4$ & $91.2 \pm 6.6$ & 5.6 \\
SP-5 & $17.2 \pm 5.1$ & $\geq 100$ & $\geq 5.8$ \\
CB-1 & $20.5 \pm 2.7$ & $24.5 \pm 5.2$ & 1.2 \\
CB-2 & $16.5 \pm 2.9$ & $27.9 \pm 3.8$ & 1.7 \\
CB-3 & $12.0 \pm 1.2$ & $32.3 \pm 2.8$ & 2.7 \\
CB-4 & $13.6 \pm 3.2$ & $27.8 \pm 6.9$ & 2.0 \\
CB-5 & $15.1 \pm 1.3$ & $17.7 \pm 4.6$ & 1.2 \\
Miltefosine & $5.9 \pm 1.8$ & $34.4 \pm 4.6$ & 5.8 \\
\hline
\end{tabular}

${ }^{\mathrm{a}} \mathrm{EC}_{50}(50 \%$ effective concentration) values refer to the activity on promastigote forms of L. amazonensis; ${ }^{\mathrm{b}} \mathrm{CC}_{50}(50 \%$ cytotoxic concentration) values refer to the cytotoxicity on peritoneal macrophages

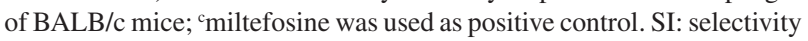
index; SP: São Paulo; CB: Cubatão.

In general, the oils from SP (population I) displayed similar anti-leishmanial activity to those obtained from $\mathrm{CB}$ (population II). However, higher activity was detected for samples SP-2 and CB-3, with 50\% effective concentration $\left(\mathrm{EC}_{50}\right)$ values of $11.8 \pm 5.2$ and $12.0 \pm 1.2 \mu \mathrm{g} \mathrm{mL}^{-1}$, respectively. In addition, the oils from $\mathrm{SP}$ showed reduced toxicity against peritoneal macrophages of BALB/c mice, with $50 \%$ cytotoxic concentration $\left(\mathrm{CC}_{50}\right)$ values higher than $75 \mu \mathrm{g} \mathrm{mL}-1$, while $\mathrm{CC}_{50}$ values determined for oils from $\mathrm{CB}$ ranged from $17.7 \pm 4.6$ to $32.3 \pm 2.8 \mu \mathrm{g} \mathrm{mL}^{-1}$. Aiming to understand the effect of the components of crude essential oils against L. amazonensis, methods that classified and weighted the influence of these constituents were developed. In a primary overview, Figure 1 exhibits the level of similarity among the essential oils from population I (SP) which ranged from 13 to $60 \%$. The essential oils from population II (CB) reached higher levels of similarity ranging from 69 to $88 \%$.

The lower values of similarity between the essential oils from populations I (SP) and II (CB) could be associated with the different constitution in both analyzed oils, as can be seen in the hierarchical clustering of studied samples (Figure 2).

The values of similarity suggest that the combination of constituents of essential oils in specific concentrations 


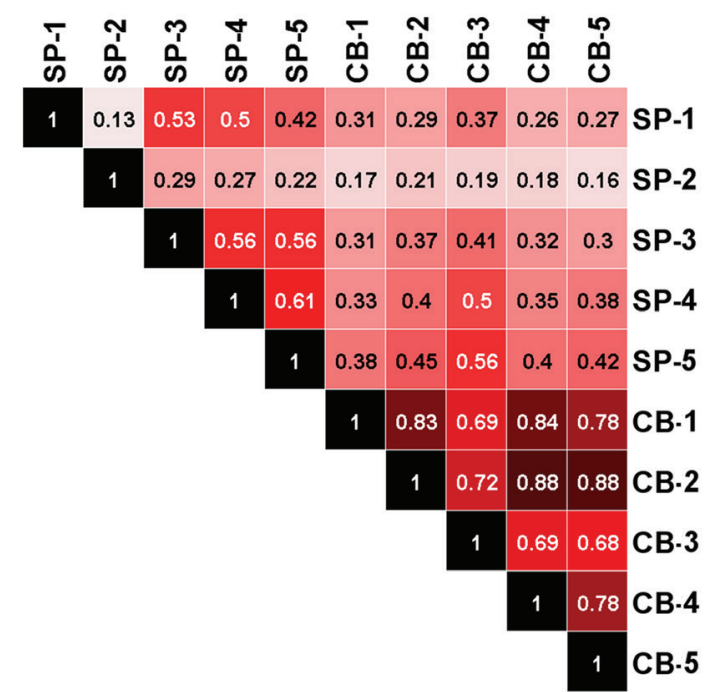

Figure 1. Similarity index of the essential oils from leaves of G. macrophylla based on the constitution of each sample and the relative percentage of their constituents. The similarity index was calculated using Jaccard index in the software Gitools 2.3.1, ${ }^{24}$ and the overlapped graph was generated and clustered with the Euclidean distance based on average scores grouping the most similar essential oils.

is strongly associated with the biological activity against L. amazonensis. The most active essential oils identified in this study (samples from the Group A: SP-2, CB-3, and CB-4) were composed of $46.7,50.1$, and $65.2 \%$ of non-oxygenated sesquiterpenes (NOS), respectively. The amounts of oxygenated sesquiterpenes (OXS) are, respectively, 35.0, 23.0, and 12.9\% (Figure 3). However, it was not possible to observe a direct linearity among the concentration of NOS, OXS, and the antileishmanial activity.

In order to reveal the influence of the constituents in the antileishmanial activity, an orthogonal partial least squarediscriminant analysis (OPLS-DA) method was developed based on the chemical constitution of each essential oil and the respective values of $\mathrm{EC}_{50}$. This strategy describes the influence of each constituent based on the relative percentage or peak area, and the contribution of these compounds to the biological activity. ${ }^{25}$ In fact, the use of MSA in metabolomics allows a systematic investigation of highly complex matrices of phytochemicals and the association of each component to the biological activity in a holistic approach. ${ }^{26,27}$ The essential oils extracted from leaves of G. macrophylla collected from populations I (SP) and II (CB) displayed chemical variations among them, resulting in unique values of $\mathrm{EC}_{50}$. In order to identify the influence of the components to antileishmanial activity two different groups were created: $\mathrm{A}\left(\mathrm{EC}_{50}\right.$ values fewer than $\left.13.6 \mu \mathrm{g} \mathrm{mL} \mathrm{m}^{-1}\right)$, and $\mathrm{B}\left(\mathrm{EC}_{50}\right.$ values higher than $\left.13.6 \mu \mathrm{g} \mathrm{mL}^{-1}\right)$, comparing the obtained $\mathrm{EC}_{50}$ values to that calculated for positive control miltefosine $\left(\mathrm{EC}_{50}=5.9 \pm 1.8 \mu \mathrm{g} \mathrm{mL}-1\right)$.

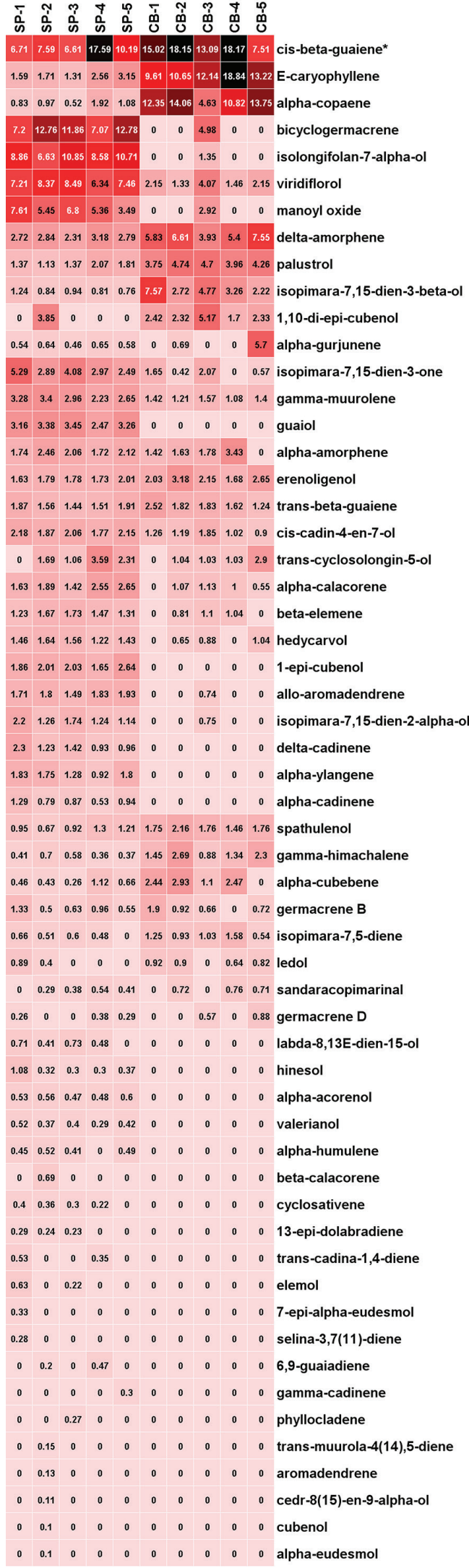

Figure 2. Hierarchical clustering of essential oils from leaves of populations I (SP) and II (CB) of G. macrophylla. The clustered analysis was performed using the software Gitools 2.3.124 with Euclidean distance according to their constitution. 


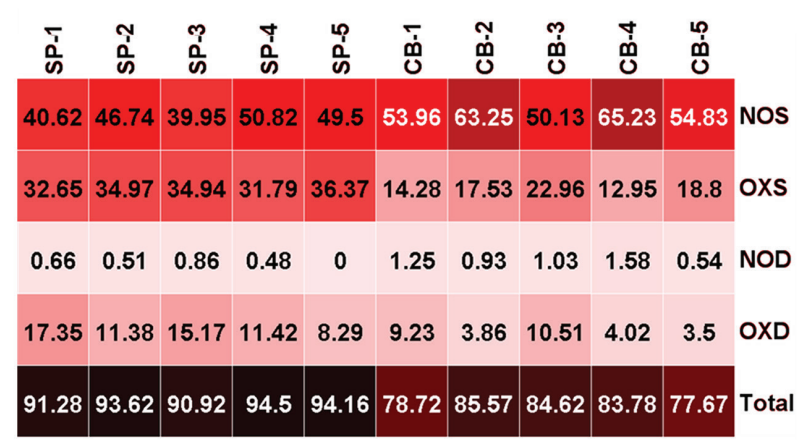

Figure 3. The percentage of components of essential oils from leaves of G. macrophylla of populations I (SP) and II (CB) according to the classes of terpenoids compounds. NOS: non-oxygenated sesquiterpenes; OXS: oxygenated sesquiterpenes; NOD: non-oxygenated diterpenes; OXD: oxygenated diterpenes.

Principal component analysis (PCA) was used in an earlier step for analyzing group separation in an unsupervised experiment, in which essential oils from populations I (SP) and II (CB) were separately projected (first component: $78.256 \%$; second component: $9.1731 \%$ of variance explained: no outliers in a $95 \%$ confidence level for the Hotelling's ellipse). Then, the classes were added and the OPLS-DA method, which explained the instances and the influence of each compound on the $\mathrm{EC}_{50}$ values, is consisted of four components (one predictive and three orthogonal: $\mathrm{n}=10 ; \mathrm{R}^{2} \mathrm{X}=0.773 ; \mathrm{R}^{2} \mathrm{Y}=0.998 ; \mathrm{Q}^{2}=0.525 ;$ confidence parameters $=0.05$ ). The obtained results by the OPLS-DA method exhibited two well-separated groups in the score scatter plot due to their different composition and range of activity. The projection showed that oils from SP and CB samples are substantially different, due to the clustering pattern (Figure 4).

For measuring the importance of each constituent to the antileishmanial activity, the results of the OPLS-DA method were further investigated based on the statistical weight of each variable. The results demonstrated that the separation was mostly influenced by the compounds 1,10-di-epicubenol, $\alpha$-amorphene (group A), and germacrene B (group B), as shown in Figure 5.

The distribution of each component through the loading scatter plot displayed that the majority of compounds are placed near pq[1] axis. The values of variable importance for the projection (VIP) demonstrated that compounds 1,10-diepi-cubenol (VIP = 2.44), germacrene B (VIP = 2.06), $\alpha$-amorphene (VIP $=2.06$ ), among others (Figure 6), were the most important variables for the statistical model.

Compounds with VIP values higher than 1 are considered the most important variables for the projection. Values of VIP from 0.99 to 0.5 are associated with the grey area, in which there is no correct definition for them in the method. Compounds with VIP lower than 0.49 are considered irrelevant for the method. ${ }^{28,29}$ The coefficient overview of the OPLS-DA model suggested for the compounds from group A 1,10-di-epi-cubenol (coefficient value: 0.20 ), $\alpha$-amorphene (coefficient value: 0.18 ), $E$-caryophyllene (coefficient value: 0.16 ), isopimara-7,15-diene (coefficient value: 0.14 ), and $\beta$-elemene (coefficient value: 0.11 ) are, together, strongly associated with the antileishmanial potential of samples SP-2, CB-3, and CB-4. These same compounds

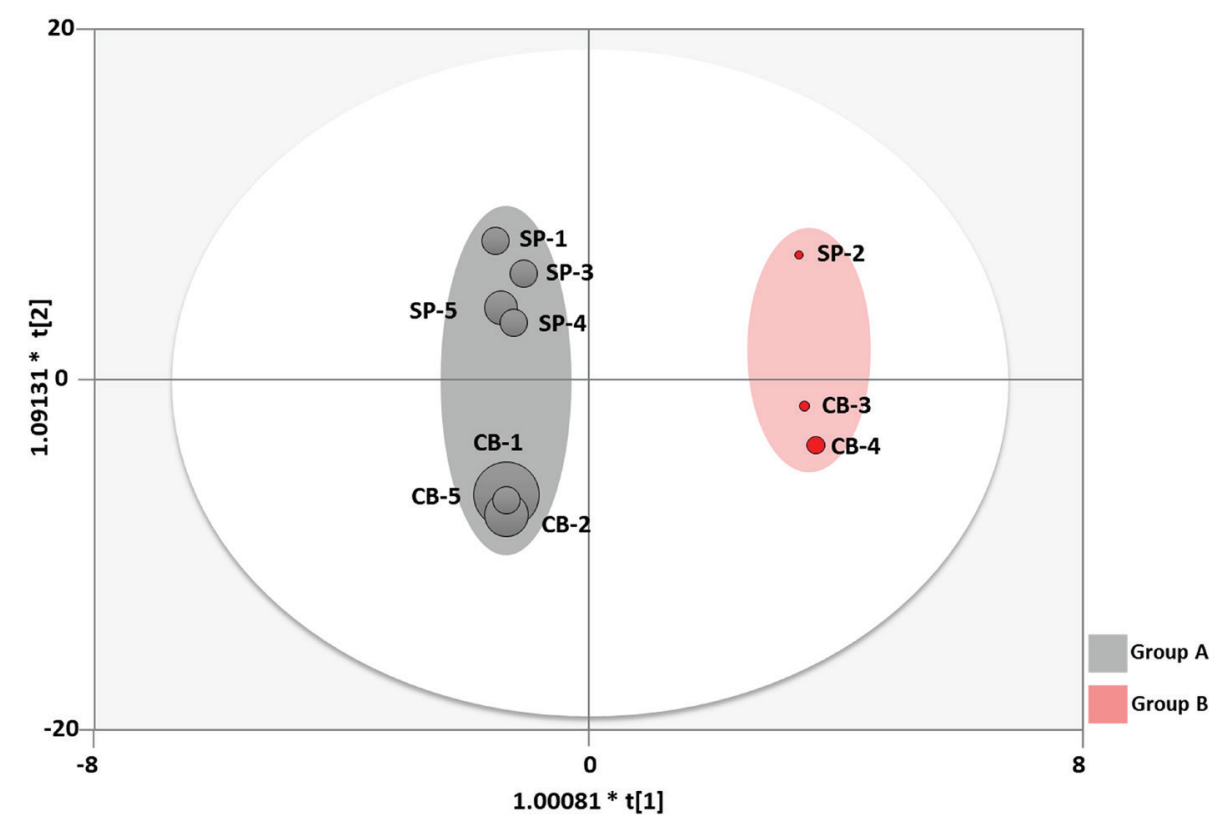

Figure 4. Score scatters plot for the samples of essential oils from leaves of G. macrophylla from populations I (SP) and II (CB), within Hotelling's T2 ellipse (95\% of confidence level). Samples are distributed in two main groups according to their $\mathrm{EC}_{50}$ values: group $\mathrm{A}\left(\mathrm{EC}_{50}<13.6 \mu \mathrm{g} \mathrm{mL} \mathrm{m}^{-1}\right)$, and group B $\left(\mathrm{EC}_{50}>13.6 \mu \mathrm{g} \mathrm{mL}-1\right)$. Each sample, represented by a circle, has its size proportional to its $\mathrm{EC}_{50}$. 


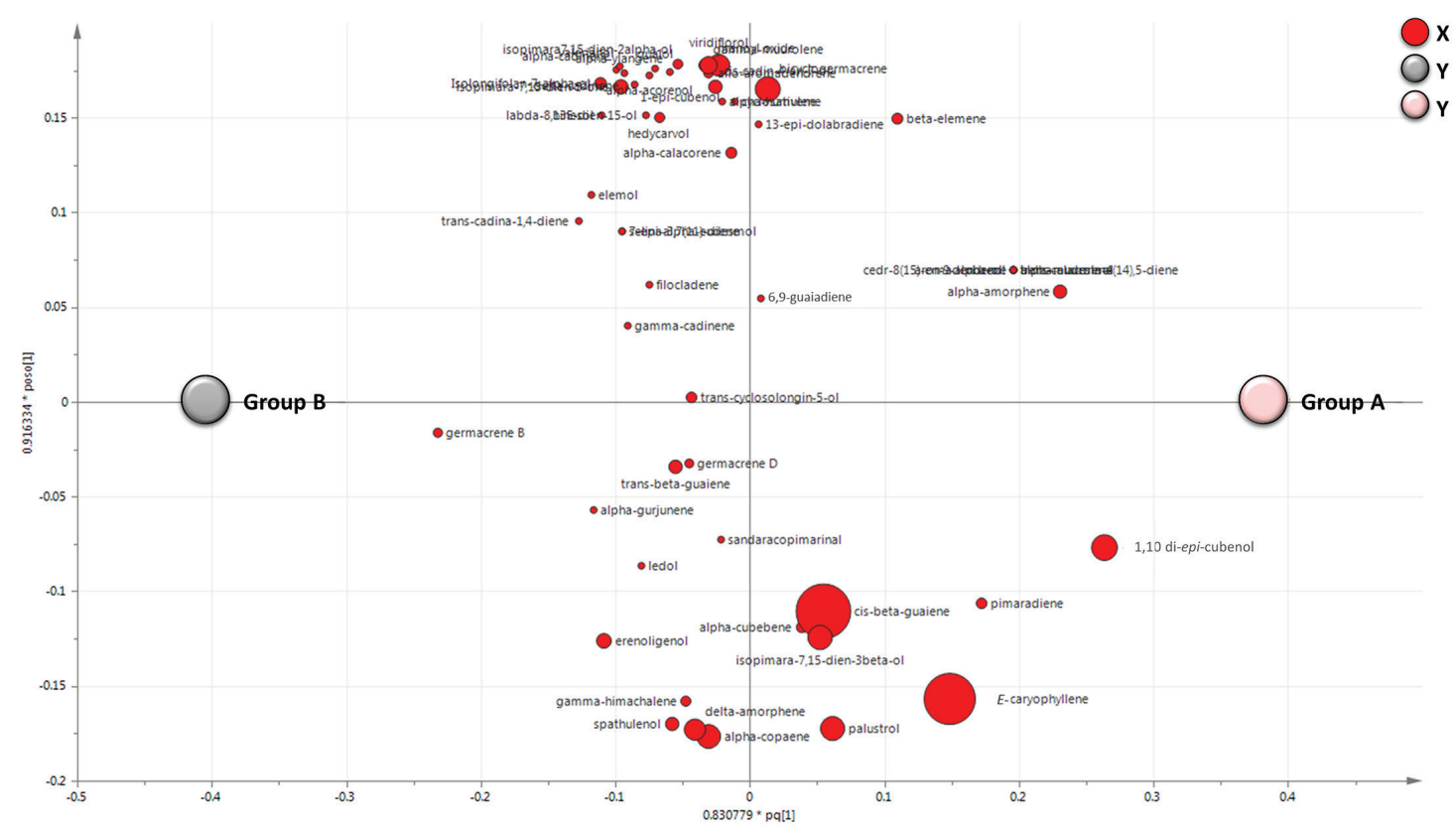

Figure 5. Loading scatters plot and the distribution of constituents from essential oils from leaves of G. macrophylla through samples of groups A and B. The $y$-axis represents the distribution of groups (according to their classification) and the $x$-axis represents the distribution of constituents. The position of each constituent is based on their statistical weight to the class, in which the closest components to the class presents a higher influence on the $\mathrm{EC}_{50}$ associated with their respective group. The size of each plot for $\mathrm{X}$ variables is represented in size by the relative percentage in the essential oils from CB-3 (the most active analyzed essential oils).

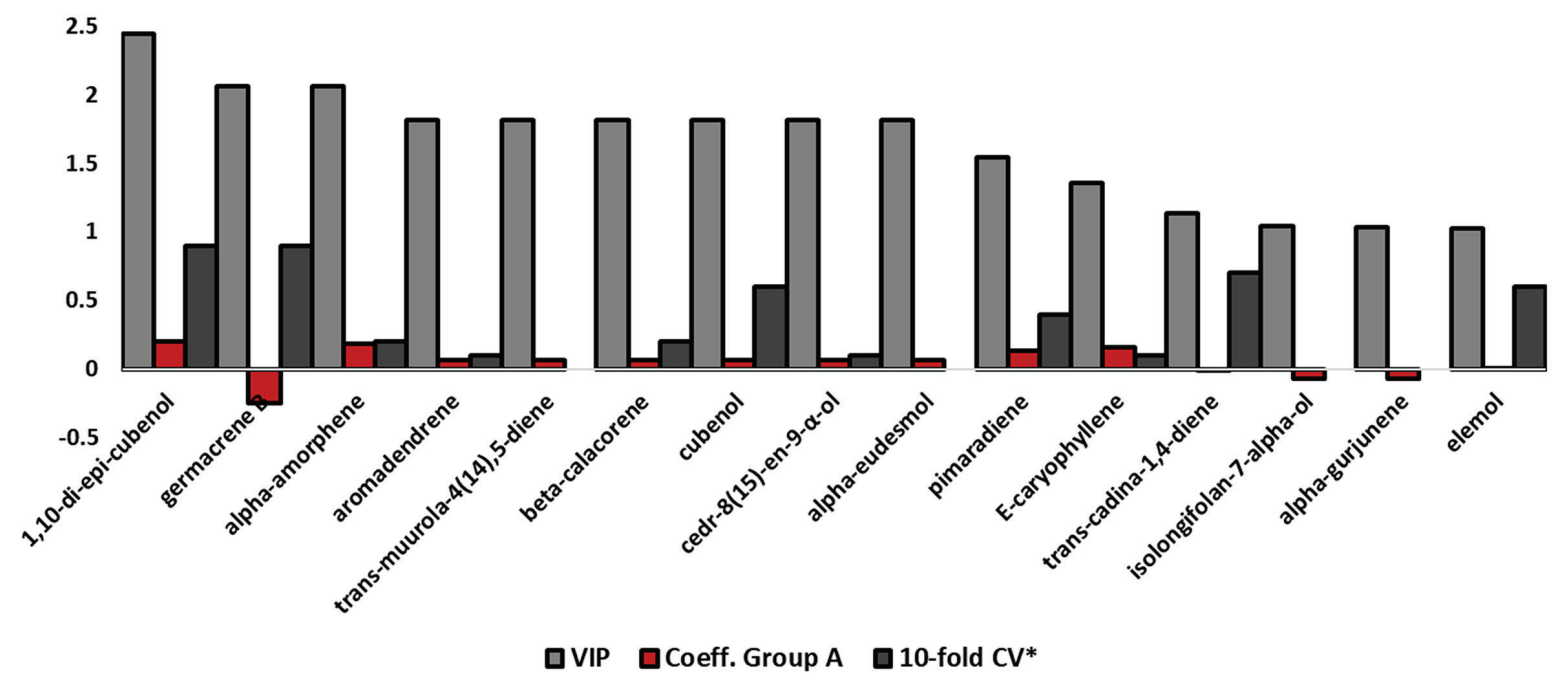

Figure 6. Values of VIP, coefficient, and 10-fold cross-validation (genetic search) for the most important variables, which explain the antileishmanial activity of essential oils from group A. The values of VIP comprehend only VIP > 1. Coefficient values are represented according to group A, in which positive values are important for the definition of this group while negative values suggest that the presence of the respective constituent decreases the biological activity of the class. *Values of 10 -fold $\mathrm{CV}$ are represented normalized from 0 to 1.

presented negative influence, e.g., negative values of the coefficient in the group B, enforcing that their presence is strongly associated with lower values of $\mathrm{EC}_{50}$. It is important to highlight that essential oils constituents are not often potent as single components, suggesting that the association of these compounds, in a synergistic point of view, play an important role in the biological activity. ${ }^{22,30}$

A subsequent approach was carried out using the software Weka $3.8,{ }^{31}$ where a dataset containing the composition, the relative percentage of each component, and class of compound was used for the purpose of selecting the best attributes that explain the antileishmanial activity. The search was made with the attribute evaluator CfsCubsetEval (which evaluates the worth of a subset of attributes by considering the individual predictive ability of each feature along with the degree of redundancy between them. Subsets of features that are highly correlated with the class while having low intercorrelation are preferred). The 
attributes were selected based on the genetic search method, which performs a search using a simple genetic algorithm, using full training set and 10 -fold cross-validation (CV) methods. The results of the genetic search elected compounds that influence the classification. The 10-fold $\mathrm{CV}$ results suggested that compounds with larger VIP and higher coefficient values (both positive and negative), such as 1,10 -di-epi-cubenol $\left(\mathrm{VIP}=2.44\right.$; coefficient $_{\text {(group A) }}=0.2$; 10-fold $\mathrm{CV}=9$; positive influence on group $\mathrm{A}$ ), germacrene $\mathrm{B}\left(\mathrm{VIP}=2.06\right.$; coefficient $_{\text {(roup A })}=-0.24 ; 10$-fold $\mathrm{CV}=9$; negative influence on group $\mathrm{A})$, and $\alpha$-amorphene $\left(\right.$ VIP $=2.06$; coefficient $_{\text {(group A) }}=0.18 ; 10$-fold $\mathrm{CV}=2$; positive influence on group $\mathrm{A}$ ), were important to explain the activity among samples of groups A and B (Figure 6).

In order to simplify these analyses, two classifiers were used to define which constituent and its relative amount could classify the essential oils from leaves of G. macrophylla in groups A and B. This investigation was carried out using two algorithms: a rule algorithm OneR, ${ }^{32}$ which uses the class for describing a simple rule that explains the dataset, and decision tree algorithm $\mathrm{J} 48$, that uses classes for generating decision trees. ${ }^{31}$ The results of OneR created a rule based on the concentration of $\alpha$-amorphene $\left(\mathrm{VIP}=2.06\right.$; $\operatorname{coefficient}_{\text {(group } \mathrm{A})}=0.18$ ), corroborating results of the OPLS-DA method. This rule describes that essential oils with relative amounts of $\alpha$-amorphene lower than $2.29 \%$ have decreased biological activity. Otherwise, a concentration of $\alpha$-amorphene higher than $2.29 \%$ implies that the essential oils act as better antileishmanial agents. The OneR method correctly classified $90 \%$ of instances (9.0/1.0).

The second strategy, based on the J48 decision tree algorithm, also resulted in $90 \%$ of correctly classified instances and pointed to 1,10-di-epi-cubenol as the most important constituent for the classification of essential oils. This sesquiterpene was found as the most important VIP for the OPLS-DA method and reached the highest value of coefficient for group A. The relative percentage of 1,10-di-epi-cubenol created a very simple decision tree with two leaves and one node, where concentrations lower than 2.4 are associated with group B (8.0/1.0) and concentrations higher than 2.4 are associated with group A (Figure 7).

Therefore, MSA consists of an important tool in order to evaluate the contribution of each constituent as proposed in the holistic approach. Based on the obtained results, it was possible to differentiate and meticulously describe the influence of each constituent of the essential oils from leaves of G. macrophylla against the promastigote forms of $L$. amazonensis based on a systematic metabolomics interpretation.



\begin{tabular}{cccc} 
& 1,10 di-epi-cubenol & $\mathrm{CE}_{50}(\mu \mathrm{g} / \mathrm{mL})$ & Group \\
\cline { 2 - 4 } SP-1 & 0 & 16.5 & B \\
SP-3 & 0 & 16.5 & B \\
SP-4 & 0 & 16.4 & B \\
SP-5 & 0 & 17.2 & B \\
CB-4 & 1.7 & 13.6 & A \\
CB-2 & 2.32 & 16.5 & B \\
CB-5 & 2.33 & 15.1 & B \\
CB-1 & 2.42 & 20.5 & B \\
SP-2 & 3.85 & 11.8 & A \\
CB-3 & 5.17 & 12 & A \\
\hline
\end{tabular}

Figure 7. Decision tree based on the constitution of the analyzed essential oils from the leaves of G. macrophylla. The constituent 1,10 -di-epi-cubenol was elected by the $\mathrm{J} 48$ algorithm in the response to the classification of the essential oils based on the $\mathrm{EC}_{50}$ values against L. amazonensis. The samples are demonstrated from the smallest to the largest concentration of 1,10-di-epi-cubenol, and the incorrectly classified instance (CB-4), in group B (8.0/1.0).

\section{Conclusions}

The essential oils from leaves of G. macrophylla, collected quarterly during one year from two different populations (I and II) at SP and CB, São Paulo State, exhibited different chemical constitution and showed distinct activity against promastigote forms of L. amazonensis, as well as toxicity against peritoneal macrophages of BALB/c mice. The respective values of $\mathrm{EC}_{50}$ were responsible for the separation in two classes (groups A and B) which revealed the most important variables associated with detected antileishmanial activity to the essential oils. The constituents with higher VIP and coefficient values to groups A (1,10-di-epi-cubenol and $\alpha$-amorphene) and $\mathrm{B}$ (germacrene $\mathrm{B}$ ) were the most important to explain the biological activity. The use of OneR and J48 algorithms created rules able to reveal the concentration of each constituent that explains the $\mathrm{EC}_{50}$ values. It was suggested by the OneR algorithm that concentrations of $\alpha$-amorphene higher than $2.29 \%$ classified the essential oils in group A. The J48 decision tree suggested that the presence of 1,10-di-epi-cubenol in concentrations higher than $2.42 \%$ in the crude oil plays an important role in the antileishmanial activity. Similarly, reduced concentration of these compounds implies in a lower potential of crude essential oils against $L$. amazonensis. In this sense, the use of MSA for discovering components with anti-leishmanial activity is valuable for creating newer alternatives revealing the potential of the plant biodiversity. Finally, our findings support a future application of this plant material to the 
development of new prototypes, based on natural products derivatives, to the treatment of leishmaniasis.

\section{Experimental}

Plant material

Fresh leaves of three neighboring specimens of G. macrophylla were collected at the University of São Paulo (USP) campus, SP (population I; 2333.928'S, $046^{\circ} 43.8561^{\prime} \mathrm{W}$ ), and at Perequê State Park, CB (population II; $23^{\circ} 50.565^{\prime} \mathrm{S}, 046^{\circ} 24.873^{\prime} \mathrm{W}$ ). Collections were performed quarterly during one year: February/2013, May/2013, August/2013, November/2013 and February/2014. Voucher specimens of each studied specimen have been deposited at São Paulo SPF herbarium (Institute of Biosciences, USP) under codes EM 238 (SP) and EM 330 (CB).

\section{Essential oils extraction and dereplication}

Fresh leaves (a pool of $100 \mathrm{~g}$ ) of G. macrophylla, collected quarterly from populations I and II, were individually subjected to hydrodistillation in a Clevenger type apparatus during $4 \mathrm{~h}$. After extraction using $\mathrm{CH}_{2} \mathrm{Cl}_{2}$ $(3 \times 2 \mathrm{~mL})$, each crude oil was dried over anhydrous $\mathrm{Na}_{2} \mathrm{SO}_{4}$. After filtration and evaporation of the solvent under reduced pressure, the samples were stored in sealed vials at low temperature $\left(-20^{\circ} \mathrm{C}\right)$. Each essential oil was analyzed in triplicate, using a Shimadzu GC-2010 gas chromatograph (GC) equipped with a flame ionization detector (FID), using an RtX-5 capillary column (5\% phenyl, 95\% polydimethylsiloxane, $30 \mathrm{~m} \times 0.25 \mathrm{~mm} \times 0.25 \mu \mathrm{m}$ film thickness; Restek) and an automatic injector (Shimadzu AOC-20i). To perform the chromatographic analysis, $1.0 \mu \mathrm{L}$ of each essential oil at $1.0 \mathrm{mg} \mathrm{mL}^{-1}$ in $n$-pentane was injected at $225^{\circ} \mathrm{C}$. Chromatographic method: temperature of $60{ }^{\circ} \mathrm{C}$ for $2 \mathrm{~min}$ followed by a slope of $3{ }^{\circ} \mathrm{C} \mathrm{min}^{-1}$ to $240^{\circ} \mathrm{C}$ and kept for $10 \mathrm{~min}$. The samples were also analyzed by GC-mass spectrometry (MS) in a Shimadzu GC-17A chromatograph interfaced with an MS-QP-2010 and quadrupole mass analyzer with impact electron ionization, operating at $70 \mathrm{eV}$, at the same conditions described above for FID-GC analysis. The essential oils were dereplicated and the identification of each compound was based on their Kovats index using National Institute of Standards and Technology (NIST) and Adams database. ${ }^{20}$

\section{Determination of the in vitro antileishmanial activity}

Each essential oil was dissolved in dimethylsulfoxide (DMSO) and filtered through a $0.22 \mu \mathrm{m}$ membrane prior to experiments. Promastigote forms of $L$. amazonensis (MHOM/BR/73/M2269) in late log stage were incubated in 96-well culture plate in Roswell Park Memorial Institute (RPMI) 1640 medium at $2 \times 10^{6}$ promastigotes per well with the essential oil in a range of 3.12 to $100 \mu \mathrm{g} \mathrm{mL}^{-1}$. The standard drug miltefosine (Sigma-Aldrich) was used as a positive control $\left(0.4\right.$ to $\left.40.0 \mu \mathrm{g} \mathrm{mL}^{-1}\right)$. Negative control group was cultivated in medium and vehicle solution (phosphate-buffered saline (PBS) $+1 \%$ DMSO) during $24 \mathrm{~h}$, at $25^{\circ} \mathrm{C}$. After this time, parasites were washed with $200 \mu \mathrm{L}$ of $0.9 \%(\mathrm{~m} / \mathrm{v})$ sodium chloride, three times with centrifugation at $1200 \mathrm{~g}, 10 \mathrm{~min}$ at $4{ }^{\circ} \mathrm{C}$, followed by addition of 3-(4,5-dimethylthiazol-2-yl)-2,5-diphenyltetrazolium bromide (MTT; $9.6 \mu \mathrm{M}$ ). Four hours later, $50 \mu \mathrm{L}$ of $10 \%$ sodium dodecyl sulfate (SDS) were added to each well. The plates were further incubated for $18 \mathrm{~h}$ and read in an enzyme-linked immunosorbent assay (ELISA) reader at $595 \mathrm{~nm} . \mathrm{EC}_{50}$ was estimated using GraphPad Prism 5.0 software. ${ }^{33-35}$

\section{Determination of cytotoxicity}

The cytotoxicity was evaluated using peritoneal macrophages of BALB/c mice. Approximately $10^{6}$ peritoneal macrophages from $B A L B / c$ mice were cultured in RPMI 1640 medium with the essential oils (3.12 to $100.00 \mu \mathrm{g} \mathrm{mL}^{-1}$ ) or miltefosine ( 0.4 to $\left.40.0 \mu \mathrm{g} \mathrm{mL}^{-1}\right)$ in 96-well plates. As the negative control, macrophages were cultivated with the vehicle solution (PBS $+1 \%$ DMSO). After $24 \mathrm{~h}$, cell viability was analyzed by the MTT method. $\mathrm{CC}_{50}$ was estimated with GraphPad Prism 5.0 software. ${ }^{33-35}$ The selectivity index (SI) was obtained through the expression $\mathrm{SI}=\mathrm{CC}_{50} / \mathrm{EC}_{50} \cdot{ }^{33}$

\section{MSA}

\section{Development of the OPLS-DA method}

The datasets were created as a matrix associating Kovats index (KI), identified compounds, relative amounts, and their respective source. The analysis was performed by the development of a supervised OPLS-DA-based method without data scaling using SIMCA-P+ 13.0.3 software. ${ }^{36}$ The OPLS-DA method was built with four components (1 predictive $\mathrm{X}-\mathrm{Y}$ and 3 orthogonal in $\mathrm{X}$ (OPLS); $\mathrm{n}=10$; $\mathrm{R}^{2} \mathrm{X}$ (cum) of 0.773; $\mathrm{R}^{2} \mathrm{Y}$ (cum) of $0.998 ; \mathrm{Q}^{2}$ of 0.525 ; confidence parameters: 0.05 ). The supervised analysis consisted of two groups based on their $\mathrm{EC}_{50}$ values: group $\mathrm{A}$ $\left(\mathrm{EC}_{50}\right.$ values lower than $13.6 \mu \mathrm{g} \mathrm{mL}-1$, more active) and group B (values of $\mathrm{EC}_{50}$ greater than $13.6 \mu \mathrm{g} \mathrm{mL}^{-1}$, less active). 


\section{Selection and classification of attributes in Weka ${ }^{31}$}

The relative percentage of each constituent of essential oils was associated with their $\mathrm{EC}_{50}$ values and the most important attributes were elected using the attribute evaluator CfsSubsetEval, which evaluates the worth of a subset of attributes by considering the individual predictive ability of each feature along with the degree of redundancy between them (number of threads: 1; poolSize: 1); search method GeneticSearch (crossoverProb: 0.6; maxGenerations 20; mutationProb 0.033; populationSize: 10; reportFrequency: 20; seed 1). The classification of attributes was carried out based on the OneR algorithm, ${ }^{32}$ and $\mathrm{J} 48$ decision tree algorithm, both set up by default. ${ }^{31}$

\section{Jaccard index heatmaps}

The software Gitools 2.3.1. ${ }^{24}$ was used for the integrative and visual analyses of the essential oils and the level of similarity among them. The dataset (saved as .csv format) was elaborated as a matrix. The heatmaps were obtained and clustered using hierarchical method applied to samples with clustering settings configured to Euclidean distance linked by average values. The color scale indicated percentage of the constituent within each sample from 0\% (Min-Color code: F2E7E7), 10\% (Mid-Color code: FE0000), and 20\% (Max-Color code: 000000). The values of Jaccard index were obtained by overlapping samples taking data from the matrix associated with the percentage of each component from the clustered analysis.

\section{Acknowledgments}

The authors acknowledge the financial support provided by the Brazilian grant agencies FAPESP (projects 2018/07885-1, 2016/00468-0 and 2016/19269-8) and CNPq for grants to J. H. G. L., P. S. This study was financed in part by CAPES (finance code 001).

\section{References}

1. Atabani, A. E.; Silitonga, A. S.; Ong, H. C.; Mahlia, T. M. I.; Masjuki, H. H.; Badruddin, I. A.; Fayaz, H.; Renewable Sustainable Energy Rev. 2013, 18, 211.

2. Komane, B. M.; Olivier, E. I.; Viljoen; A. M.; Phytochem. Lett. 2011, 4,1 .

3. Nguyen, N. Y. T.; Dang, P. H.; Nguyen, V. T. T.; Dang, P. H.; Tran, Q. L.; Nat. Prod. Res., in press, DOI: 10.1080/14786419.2018.1479700.

4. Zanetti, R.; Abreu, C. S.; Silveira, S. H. P.; Andrade, E. D.; Sci. Agric. 2017, 74, 492.

5. Lago, J. H. G.; Roque, N. F.; Phytochemistry 2002, 60, 329.
6. Lago, J. H. G.; Brochini, C. B.; Roque, N. F.; Phytochemistry 2000, 55, 727.

7. Lago, J. H. G.; Roque, N. F.; J. Braz. Chem. Soc. 2005, 16, 643.

8. Pereira, C.; Barreto Jr., C. B.; Kuster, R. M.; Simas, N. K.; Sakuragui, C. M.; Porzel, A.; Wessjohann, L.; Quim. Nova 2012, 35, 1123.

9. Lago, J. H. G.; Cornélio, M. L.; Moreno, P. R. H.; Apel, M. A.; Limberger, R. P.; Henriques, A. T.; Roque, N. F.; J. Essent. Oil Res. 2005, 17, 84.

10. Lago, J. H. G.; Reis, A. A.; Roque, N. F.; Flavour Fragrance J. 2002, 17, 255.

11. Lago, J. H. G.; Roque, N. F.; J. Essent. Oil Res. 2002, 14, 12.

12. Lago, J. H. G.; Soares, M. G.; Batista-Pereira, L. G.; Silva, M. F. G. F.; Correa, A. G.; Fernandes, J. B.; Vieira, P. C.; Roque, N. F.; Phytochemistry 2006, 67, 589.

13. Anversa, L.; Tiburcio, M. G. S.; Richini-Pereira, V. B.; Ramirez, L. E.; Rev. Assoc. Med. Bras. 2018, 64, 281.

14. Sundar, S.; Chakravarty, J.; Expert Opin. Pharmacother. 2015, 16, 237.

15. Santos, D. O.; Coutinho, C. E. R.; Madeira, M. F.; Bottino, C. G.; Vieira, R. T.; Nascimento, S. B.; Bernardino, A.; Bourguignon, S. C.; Corte-Real, S.; Pinho, R. T.; Rodrigues, C. R.; Castro, H. C.; Parasitol. Res. 2008, 103, 1.

16. Schmidt, T. J.; Khalid, S. A.; Romanha, A. J.; Alves, T. M. A.; Biavatti, M. W.; Brun, R.; Da Costa, F. B.; de Castro, S. L.; Ferreira, V. F.; de Lacerda, M. V. G.; Lago, J. H. G.; Leon, L. L.; Lopes, N. P.; Amorim, R. C. N.; Niehues, M.; Ogungbe, I. V.; Pohlit, A. M.; Scotti, M. T.; Setzer, W. N.; Soeiro, M. N. C.; Steindel, M.; Tempone, A. G.; Curr. Med. Chem. 2012, 19, 2128.

17. Schimidt, T. J.; Khalid, S. A.; Romanha, A. J.; Alves, T. M. A.; Biavatti, M. W.; Brun, R.; Da Costa, F. B.; de Castro, S. L.; Ferreira, V. F.; de Lacerda, M. V. G.; Lago, J. H. G.; Leon, L. L.; Lopes, N. P.; Amorim, R. C. N.; Niehues, M.; Ogungbe, I. V.; Pohlit, A. M.; Scotti, M. T.; Setzer, W. N.; Soeiro, M. N. C.; Steindel, M.; Tempone, A. G.; Curr. Med. Chem. 2012, 19, 2176.

18. Nakatsu, T.; Lupo Jr., A. T.; Chinn Jr., J. W.; Kang, R. K. L. In Studies in Natural Products Chemistry, vol. 21, Part B; Atta-ur-Rahman, ed.; Elsevier: Amsterdan, Netherlands, 2000, p. 571.

19. Ueno, A. K.; Barcellos, A. F.; Costa-Silva, T. A.; Mesquita, J. T.; Ferreira, D. D.; Tempone, A. G.; Romoff, P.; Antar, G. M.; Lago, J. H. G.; Fitoterapia 2018, 125, 55.

20. Adams, R. P.; Identification of Essential Components by Gas Chromatography/Mass Spectroscopy; Allured Corp.: Carol Stream, 2009.

21. Lago, J. H. G.; Romoff, P.; Pirani, J. R.; Roque, N. F.; J. Essent. Oil Res. 2007, 19, 338.

22. Bosquiroli, L. S. S.; Ferreira, A. C. S.; Farias, K. S.; da Costa, E. C.; Matos, M. F. C.; Kadri, M. C. T.; Rizk, Y. S.; Alves, F. M.; Perdomo, R. T.; Carollo, C. A.; Arruda, C. C. P.; Pharm. Biol. 2017, 55, 2285. 
23. Monzote, L.; Geroldinger, G.; Tonner, M.; Scull, R.; De Sarkar, S.; Bergmann, S.; Bacher, M.; Staniek, K.; Chatterjee, M.; Rosenau, T.; Gille, L.; Phytother. Res. 2018, 32, 1729.

24. Perez-Llamas, C.; Lopez-Bigas, N.; PLoS One 2011, 6, e19541.

25. Worley, B.; Powers, R.; Curr. Metabolomics 2013, 1, 92.

26. Baldim, J. L.; Silveira, J. G. F.; Almeida, A. P.; Carvalho, P. L. N.; Rosa, W.; Schripsema, J.; Chagas-Paula, D. A.; Soares, M. G.; Luiz, J. H. H.; Ind. Crops Prod. 2018, 112, 821.

27. Yuliana, N. D.; Khatib, A.; Choi, Y. H.; Verpoorte, R.; Phytother. Res. 2011, 25, 157.

28. Chagas-Paula, D. A.; Zhang, T.; Da Costa, F. B.; Edrada-Ebel, R.; Metabolites 2015, 5, 404.

29. Yuliana, N. D.; Khatib, A.; Verpoorte, R.; Choi, Y. H.; Anal. Chem. 2011, 83, 6902.

30. Herman, A.; Tambor, K.; Herman, A.; Curr. Microbiol. 2016, $72,165$.

31. Witten, I. H.; Frank, E.; Hall, M. A.; Practical Machine
Learning Tools and Techniques, $3^{\text {rd }}$ ed.; Morgan Kaufmann: London, 2011.

32. Holte, R. C.; Mach. Learn. 1993, 11, 63.

33. Dal Picolo, C. R.; Bezerra, M. P.; Gomes, K. S.; Passero, L. F. D.; Laurenti, M. D.; Martins, E. G. A.; Sartorelli, P.; Lago, J.

H. G.; Fitoterapia 2014, 97, 28.

34. Poorrajab, F.; Ardestani, S. K.; Foroumadi, A.; Emami, S.; Kariminia, A.; Behrouzi-Fardmoghadam, M.; Shafiee, A.; Exp. Parasitol. 2009, 121, 323.

35. GraphPad Prism version 5.00 for Windows; GraphPad Software, La Jolla, CA, USA, 2007.

36. Umetrics; SIMCA-P+ 13.0.3; Umetrics, Sweden, 2014.

Submitted: September 17, 2018 Published online: February 27, 2019 